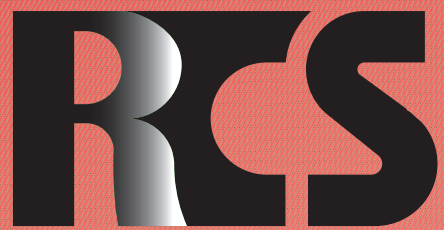

Depósito legal ppi $201502 Z U 4662$

Esta publicación científica en formato digital es continuidad de la revista impresa Depósito Legal: pp $197402 Z U 789$

- ISSN: 1315-9518 • ISSN-E: 2477-9431

Revista de Ciencias Sociales

Universidad del Zulia. Revista de la Facultad de Ciencias Económicas y Sociales Vol. XXVII. No. 2

Abril-Junio 2021

Esta publicación científica en formato digital es continuidad de la revista impresa Depósito Legal: pp $197402 Z$ Z789 ISSN: 1315-9518 


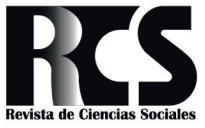

Revista de Ciencias Sociales (RCS). FCES - LUZ Vol. XXVII, No. 2, 2021, pp. 515-518 Abril-Junio

- ISSN: 1315-9518 • ISSN-E: 2477-9431

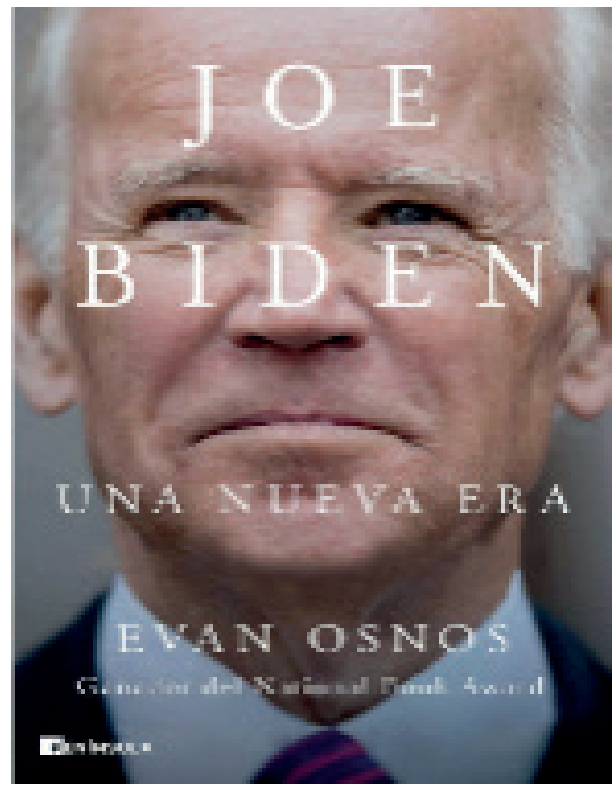

\section{Joe Biden: Una nueva era}

\author{
Autor: Evan Osnos \\ Editorial: Ediciones Península \\ 2020. pp. 121. \\ ISBN: 978-84-9942-963-2 (epub)
}

Joe Biden: The Life, the Run, and What Matters Now. Sin mayor preámbulo, ya el título, en su versión original al inglés, remite a una urgencia: El candidato demócrata con una carrera política de más de 40 años que habría de colocarlo en la tribuna de los conservadores terminará, por la coyuntura del momento, como una suerte de veleta, moviéndose a la izquierda. La biografía breve, con firma de Evan Osnos, periodista de política exterior del Time New Yorker y ganador del Pulitzer, relata en ocho capítulos el ejercicio político que legitima al candidato adversario de Donald Trump.

Desde el drama familiar, la personalidad política que roza peligrosamente con el carisma de los líderes populistas, sus imprudencias discursivas, su ambición personal y una suerte de redención o madurez política que casualmente llega con su candidatura presidencial, el texto ofrece además, una caracterización del contexto que justifica el pragmatismo en el cambio de rumbo de Biden. Estos pudieran ser los tópicos centrales de esta producción.

Si el título en inglés es elocuente, la versión en español denuncia lo que a grandes rasgos está operando en la política norteamericana: Joe Biden: Una nueva era. Al mejor estilo periodístico, el autor inicia su libro 
titulando el primer capítulo como una noticia de primera página, pero ornamentado con un latinazo que, entendiéndolo o no, llama a la lectura, ¡Anno Horribilis! (las exclamaciones son propias). De entrada, el autor plantea la piedra angular de su publicación, el drama personal de Biden en 1988, afectado por un aneurisma que coloca en jaque su designación política en el senado del Congreso de los Estados Unidos. Luego, en una recurrencia temporal pasado-presente y viceversa, Osnos coloca en el tapete la crítica republicana con respecto a la edad del aspirante demócrata a la Casa Blanca, el gobierno de Trump y su relación gobierno federal y gobernaciones y el manejo de la pandemia.

En ese contexto, surge Joe Biden, un candidato que está lejos de representar el cambio que aspira un sector importante del país. Entre Trump y este, las opciones terminaban siendo malas según se entiende en el discurso del trabajo, el dramatismo lo expuso Osnos (2020) de esta manera:

Fue como si un camarero hubiera vuelto de la cocina con la noticia de que los platos del día se habían terminado y solo quedaban copos de avenas, (aunque, por supuesto, estaba también la opción de pedir más veneno para ratas). (p.7)

La condición etaria tiene un atractivo en el abordaje que le da el autor, en cuanto que este plantea una brecha generacional entre quienes cumplen el rol del amplio sector electoral con una media de edad de 38 años, en contraposición a quienes componen el senado que en promedio están en los 65 años. Visto así, Osnos señala que Biden es visto por estos como representante del Ancien Regime. Sin embargo, el hombre veleta (en palabras del autor), se fue moviendo del centro a la izquierda, en concordancia a la dirección donde soplaba el viento.

Estados Unidos ya no es el sueño americano, dice Evan, el abismo generacional tiene sus razones entre una población con baja natalidad, grupos reducidos en las escuelas, altas tasas de inserción en las universidades, facilidad de préstamos y programas de trabajo, el New Deal y la Ley de Reinserción Militar, ... De allí viene Biden. En contraposición a una generación que muestra la cara del norteamericano del presente, donde una población nada desdeñable entre los 25 a 38 años, vive con sus padres, ya esto pareciera resumir el contexto actual en que se mueve la juventud estadounidense.

Pero al candidato demócrata, se le adicionan otras características que lo sitúan al margen de una buena opción, de forma lapidaria afirma la poca instrucción de Biden, en gran parte el libro será recurrente con ello y no escatimará en testimonios para dar prueba de su falta de formación en diversas áreas y en lo poco formal para atender casos en particular, “...pronunció en el Senado un apasionado discurso sobre un tema que no le era demasiado familiar - los pozos petroleros - y uno de sus oponentes se lo hizo notar. ( ¿Ha visto alguna vez un pozo, senador Biden?»)" (Osnos, 2020 , p.35).

Tienes que crecer, es el título del tercer capítulo. El político inmaduro y satirizado por sus colegas es el tema desarrollado en este espacio, una especie de mitomanía con la finalidad de equipararse con los políticos de la época. Desde logros académicos inexistentes:

Biden se jactaba de haber recibido «una beca académica completa» y de haber «terminado entre los mejores de mi clase», cuando ninguna de las dos cosas era cierta. Cuando le preguntaron por ello, se disculpó y dijo: «Exagero cuando estoy enfadado, pero no voy por la vida diciéndole a la gente cosas sobre mí que no son ciertas». (Osnos, 2020, p.35)

Hasta acciones heroicas en el campo de batalla, "Una vez dijo que le habían disparado en Irak. Cuando se cuestionó su afirmación, lo matizó un poco..." (p.35), la cuestión era que estaba cerca del disparo.

$\mathrm{Su}$ llegada a la vicepresidencia planteó una dicotomía entre las personalidades de Obama y Biden, según el autor. A pesar de 
su característica imprudencia, destacaba su vida familiar, elemento que será explotado o expuesto en su campaña presidencial unos años más tarde. Sin embargo, Osnos recalca la imagen de hombre tonto que deja Biden tras su camino. "Durante el verano, una encuesta de Pew Research Center y el Washington Post, pidió a la gente que describiera a Biden con una sola palabra; las respuestas más frecuentes, en números casi idénticos fueron bueno e idiota" (Osnos, 2020, p.42).

A partir del capítulo 5, Evan Osnos muestra la redención de Biden, poco a poco la balanza se va inclinando hacia sus dotes, aquel político imprudente, ignaro, mitómano y tonto va desapareciendo. La tradición estadounidense entiende que la Vicepresidencia no es el puesto en la administración de un gobierno más notable. Pero las relaciones interpersonales de este, cultivadas en su ejercicio como senador encargado en política exterior desde hacía muchos años, se ganó su designación como enviado a negociar el conflicto iraquí.

Aunque su gestión fracasa, el libro hace alusión a una propuesta cuestionada en su momento, pues una decisión de tal magnitud conllevaría a la desintegración de Irak. "Pergeñaron una idea para un sistema federal con tres regiones semiautónomas para los suníes, los chiíes y los kurdos, basada en parte en la experiencia de Biden en Bosnia" (Osnos, 2020 , p .65). Pero, dice el autor;

(Después le pregunté a Michael O’Hanlon, experto en política exterior de la Brookings Institution, qué opinaba de la propuesta del sistema federal. Me contestó: «No es una idea descabellada; nunca lo fue. Aún es posible que ese sea el último recurso».). (p.65)

Lo cierto es que, este deja ver que Biden es un hombre que hace política a su modo, pero sabe hacer política. Entre deslices y monólogos extenuantes, resalta una frase, bastante atrevida, soltada por el vicepresidente al premier del estado de Israel Benjamín Netanyau, "...no tiene sentido morir en una cruz pequeña", en alusión a invitarlo a una paz que abarcara a todo el medio oriente. Dice Osnos (2020):

Ron Dermer, el embajador israelí en
Estados Unidos en aquel momento, lo recordó así: «Estamos en Jerusalén, tenemos un vicepresidente católico y un primer ministro judío, y va y le dice (...) El primer ministro se echó a reír. Tengo que decirlo, para mí es la muestra de entendimiento de la realidad política de Israel más sucinta que he oído». (p.59)

Este trabajo muestra a Biden como el hombre del desenfado, del carisma y el antiprotocolo, características comunes en el populismo en cuanto al mercadeo de la imagen. Pese a no ser taxativo el autor en esto, pudiera inferirse.

Los últimos tres capítulos están dedicados a la candidatura de Biden, el problema de la edad, el apoyo del partido y Obama, Hilary Clinton y la enfermedad de su hijo. La encrucijada del candidato la maneja Osnos desde tres perspectivas: La vida familiar, alterada por el cáncer de uno de sus hijos y que al final llega a ser determinante para abandonar sus aspiraciones presidenciales en el 2016; las alianzas con personalidades clave del partido y su convicción de ser presidente a pesar de la edad. El triunfo de Trump allana el camino al debilitar la imagen de Hilary como posible candidata. La figura de Sanders, el candidato del cambio que captaba la atención de grupos y organizaciones de clara tendencia de izquierda, pero poco agradable para el conservadurismo demócrata y el republicanismo descontento con la política trumpista, es un escollo que compromete el centrismo de Biden y lo mueve en dirección a donde el viento sopla, el progresismo.

La candidatura, según Evan Osnos, fue concebida como la batalla por el alma estadounidense. La lucha contra Trump, implicó alianzas con sectores progresista de la izquierda norteamericana como Alexandra Ocasio Cortez del movimiento ambientalista, AiJenPoo del área laboral y la figura de Khamala Harris, aunque liberal, es el simbolismo de la representación de los migrantes. Lo cierto es que, para el autor, Biden decide abandonar el centro en procura de captar los votos que estaban ganados por Sanders.

Osnos concluye el libro exponiendo lo 
sustancial del programa del candidato nacido en Pensilvania, la reintegración a la OMS y el Acuerdo de París, la eliminación de las restricciones migratorias desde los países musulmanes, la extensión del programa gratuito de atención sanitaria Medicare a inmigrantes indocumentados. En resumidas cuentas, la política demócrata hacia el integracionismo de la cual Trump alejo al país en sus cuatro años de ejercicio.

Es un trabajo que vale la pena leer en función de comprender el contexto sociopolítico en la cual se dieron las elecciones más atípicas de los EEUU. La potencial ruptura del orden bipartidista, con el ascenso de una tercera fuerza que aún se encuentra gestándose a la sombra del partido demócrata, pero con argumentos y suficientes seguidores como para independizar su proyecto. Pareciera que el progresismo, según lo deja entrever Evan Osnos, ya camina por los pasillos de la Casa Blanca.

Profe. Richard O. López Álvarez

Profesor del Departamento de Geografía e Historia de la Universidad Pedagógica Experimental Libertador (UPEL)

Instituto Pedagógico de Caracas (IPC).

Miembro del Centro de Investigaciones Históricas

Mario Briceño Iragorry (CIHMBI)

Miembro del Consejo Editorial de la Revista Tiempo y Espacio

E-mail: riloale@gmail.com

ORCID: https://orcid.org/0000-0003-1242-6925 